\title{
Mechanistically Compatible Mixtures of Bacterial Antagonists Improve Biological Control of Fire Blight of Pear
}

\author{
V. O. Stockwell, K. B. Johnson, D. Sugar, and J. E. Loper
}

First, second, and fourth authors: Oregon State University, Department of Botany and Plant Pathology, Corvallis 97331; third author: Southern Oregon Research and Extension Center, Oregon State University, Medford 97502; and fourth author: United States Department of Agriculture-Agricultural Research Service, Horticultural Crops Research Laboratory, 3420 NW Orchard Avenue, Corvallis, OR 97330. Accepted for publication 3 September 2010.

\begin{abstract}
Stockwell, V. O., Johnson, K. B., Sugar, D., and Loper, J. E. 2011. Mechanistically compatible mixtures of bacterial antagonists improve biological control of fire blight of pear. Phytopathology 101:113-123.

Mixtures of biological control agents can be superior to individual agents in suppressing plant disease, providing enhanced efficacy and reliability from field to field relative to single biocontrol strains. Nonetheless, the efficacy of combinations of Pseudomonas fluorescens A506, a commercial biological control agent for fire blight of pear, and Pantoea vagans strain C9-1 or Pantoea agglomerans strain Eh252 rarely exceeds that of individual strains. A506 suppresses growth of the pathogen on floral colonization and infection sites through preemptive exclusion. C9-1 and Eh252 produce peptide antibiotics that contribute to disease control. In culture, A506 produces an extracellular protease that

tested in five replicated field trials comparing biological control of fire blight using strain A506 and A506 aprX::Tn5, an extracellular proteasedeficient mutant, as individuals and combined with C9-1 or Eh252. On average, mixtures containing A506 aprX::Tn5 were superior to those containing the wild-type strain, confirming that the extracellular protease of A506 diminished the biological control activity of C9-1 and Eh252 in situ. Mixtures of A506 aprX::Tn5 and C9-1 or Eh252 were superior to oxytetracycline or single biocontrol strains in suppressing fire blight of pear. These experiments demonstrate that certain biological control agents are mechanistically incompatible, in that one strain interferes with the mechanism by which a second strain suppresses plant disease. Mixtures composed of mechanistically compatible strains of biological control agents can suppress disease more effectively than individual biological control agents.
\end{abstract} degrades the peptide antibiotics of C9-1 and Eh252. We hypothesized that strain A506 diminishes the biological control activity of C9-1 and Eh252, thereby reducing the efficacy of biocontrol mixtures. This hypothesis was
Additional keywords: Erwinia herbicola, herbicolin, Pantocin, Pyrus, stigma.
Mixtures of biological control agents can be superior to individual strain inoculants for the management of plant disease (9). In this study, we evaluated mixtures of bacterial antagonists for the suppression of fire blight disease of pear caused by Erwinia amylovora. This bacterial pathogen typically establishes epiphytic populations on stigmatic surfaces of pear flowers in the spring, prior to migration to the nectary and ingress of tissues through the nectarthodes (32). This stage of the disease process offers a targeted stage for control: the exclusion of the pathogen from floral surfaces or subsequent suppression of epiphytic growth of the pathogen on stigmas $(9,15,37)$. We focused our analysis of mixtures on two biological control agents of fire blight that are registered for management of fire blight. The commercial product BlightBan A506 (NuFarm Americas, Burr Ridge, IL) contains Pseudomonas fluorescens A506 (A506) as the active ingredient (29). A506 provided $\approx 50$ to $80 \%$ control of fire blight in trials in noninoculated commercial orchards in California (1517) but did not provide significant control of fire blight in inoculated experimental orchards in Oregon (27). The bacterium suppresses fire blight by competitive exclusion of the pathogen from flowers (37). Pantoea vagans strain C9-1 is registered with the United States Environmental Protection Agency for commercial use for suppression of fire blight (BlightBan C9-1;

Corresponding author: V. O. Stockwell

E-mail address: stockwev@science.oregonstate.edu

doi:10.1094/PHYTO-03-10-0098

(C) 2011 The American Phytopathological Society
NuFarm Americas). In inoculated trials in Oregon, C9-1R (a rifampicin-resistant derivative) significantly reduced the incidence of fire blight by $42 \%$ compared with water-treated controls (27). C9-1 is one of many strains of Pantoea agglomerans and Pantoea vagans that have been studied as biological control agents for fire blight $(5,14,20,22,27,31,33,39-41)$. Many strains of these species produce antibiotics in culture that inhibit growth of $E$. amylovora (5,14,22,35,39-41). Pantoea agglomerans strain Eh252 and Pantoea vagans C9-1 produce antibiotics called mccEh252 and herbicolin O, respectively, which are synonymous to Pantocin A, a histidine-reversible tripeptide antibiotic of Pantoea agglomerans strain Eh318 (3,5-7,35,36,41). The antibiotic has a key role in the biological control of fire blight by strain Eh252 (26).

Previously, we evaluated fire blight control with a 1:1 intergeneric mixture of A506 and C9-1R in pathogen-inoculated orchard trials in Oregon (27). Using replacement series experiments, we found that the two antagonists co-colonize flowers well, often establishing greater populations than those achieved by single-strain inoculants. The level of control by the mixture was $32 \%$, intermediate to control by A506 or C9-1R applied as single-strain inoculants (27). These experiments indicated that C9-1R and A506 were ecologically compatible but that the mixture did not provide additive or synergistic disease control (27). Vanneste et al. (34) in New Zealand similarly found that combining Eh252 with A506 resulted in co-colonized flowers and provided intermediate levels of control of fire blight compared with single-strain inoculants in pathogen-inoculated trials. In three trials, Eh252 reduced the incidence of fire blight by $35 \%$ and A506 by 20\%, and the mixture of A506 and Eh252 reduced the disease incidence by $27 \%$ (34). We proposed that the lower- 
than-expected level of disease control by mixtures of A506 with strains of Pantoea spp. is due to mechanistic incompatibility, whereby the activity of one antagonist interferes with a mechanism of antagonism employed by the other antagonist (27).

In this study, we tested the hypothesis that mechanistic compatibility is an important consideration in designing mixtures of biological control agents for plant disease management. Earlier, we were fortunate to detect a potential source of mechanistic incompatibility when we discovered that the extracellular protease of A506 inactivated the peptide antibiotic common to C9-1 and Eh252 (1). A mutant of A506 deficient in production of the extracellular protease (A506 aprX::Tn5) did not inactivate the antibiotic of $\mathrm{C} 9-1$ and Eh252 and the mutant, like the parental strain, was insensitive to the peptide antibiotic (1). We concluded that the resistance of A506 to the antibiotics of C9-1 and Eh252 was intrinsic and that the extracellular protease did not play a role in resistance of A506 to this antibiotic of Pantoea spp. The objective of this research was to evaluate the protease-deficient mutant of A506 for control of fire blight alone and in combination with C9-1 or Eh252 in pear orchards. A portion of the research on the efficacy of Eh252 as a biological control agent was published previously (26).

\section{MATERIALS AND METHODS}

Bacterial strains. Pseudomonas fluorescens strain A506 was obtained from S. Lindow (University of California-Berkeley). The strain is resistant to rifampicin and streptomycin at $100 \mu \mathrm{g} / \mathrm{ml}$ (15-17,29). The kanamycin-resistant derivative A506 aprX::Tn5, previously called M1 (1), has a single Tn5-insertion in $a p r X$ which encodes for an extracellular metalloprotease. A506 aprX::Tn5 does not inactivate the antibiotic of Eh252 or herbicolin O of C9-1 in culture (1). Pantoea vagans (formerly Pantoea agglomerans or E. herbicola) strain C9-1S $(5,23,25)$ is a spontaneous mutant resistant to rifampicin and streptomycin at $100 \mu \mathrm{g} / \mathrm{ml}$. Pantoea agglomerans Eh252 was obtained from S. Beer (Cornell University) and is sensitive to rifampicin and streptomycin (26). E. amylovora strain $153 \mathrm{~N}$ (Ea153N) is a pathogenic, spontaneous nalidixic acid-resistant $(100 \mu \mathrm{g} / \mathrm{ml})$ mutant of Ea153 and has been used in numerous field trials $(8,10,11$, $19,20,22,24-27)$. Each bacterial strain was stored in nutrient broth with $15 \%$ glycerol at $-80^{\circ} \mathrm{C}$ until use.

Nutrient utilization profiles of antagonist strains. The capacity of strains of A506 and A506 aprX::Tn5 to catabolize nutrients was assessed with Biolog GN plates and Phenotype
Microarray (2) assays plates PM1 to PM20 by the PMServices of Biolog (Hayward, CA). The Biolog GN plate experiments were conducted according to the recommendations of the manufacturer. Duplicate plates of all Biolog plates were incubated at $22^{\circ} \mathrm{C}$. Results were provided from readings taken after $48 \mathrm{~h}$ of incubation.

Experimental design for orchards. Field experiments were conducted in 0.5-ha blocks of pear (Pyrus communis L. cvs. Bartlett and Bosc) at the Oregon State University Botany and Plant Pathology Field Laboratory near Corvallis, OR and the Southern Oregon Research and Extension Center near Medford, OR (Table 1).

Treatments. Treatments were assigned to individual trees in a randomized complete block design. Assignment of trees to blocks was based on relative bloom density and location within an orchard. Each treatment was randomly assigned to individual trees in five replicate blocks, except in the 1999 trial in Medford, which contained four replicate blocks.

Eh252, C9-1S, and A506 were cultured for 3 to 4 days at $25^{\circ} \mathrm{C}$ on nutrient agar (Difco Laboratories, Detroit) containing $1 \%$ glycerol and A506 aprX::Tn5 was cultured on the same medium amended with kanamycin at $50 \mu \mathrm{g} / \mathrm{ml}$. Bacteria were scraped from the agar surface and suspended in sterile $20 \mathrm{mM}$ phosphate buffer at a cell concentration of $\approx 1 \times 10^{10} \mathrm{CFU} / \mathrm{ml}$ based on turbidity readings (Bausch and Lomb Spectronic 20), and the concentrated stock solution was transported to the field in an ice chest. In the field plots, bacterial suspensions were diluted with water (local groundwater sources) to appropriate concentrations prior to spraying. The titers of the applied suspensions were confirmed after treatment by dilution plating.

Trees were sprayed at $30 \%$ bloom and again at $70 \%$ bloom at sunrise with bacterial antagonists until near run-off using 12-liter backpack sprayers fitted with adjustable nozzles attached to a handheld spray wand (Table 1). Treatments applied were (i) A506, (ii) A506 aprX::Tn5, (iii) Eh252, and (iv) C9-1S, with each strain applied at $1 \times 10^{8} \mathrm{CFU} / \mathrm{ml}$. Mixtures consisted of (i) Eh252 and A506, (ii) Eh252 and A506 aprX::Tn5, (iii) C9-1S and A506, and (iv) C9-1S and A506 aprX::Tn5, with each strain applied at a concentration of $5 \times 10^{7} \mathrm{CFU} / \mathrm{ml}$ or a total dose of $1 \times 10^{8} \mathrm{CFU} /$ $\mathrm{ml}$. In all, $\approx 2$ to 4 liters of a bacterial suspension was applied to individual trees. Additional trees in each plot were treated with water or streptomycin sulfate (Bac-Master 17\%, $100 \mu \mathrm{g} / \mathrm{ml}$ a.i.) (Pace International, Seattle) at $70 \%$ bloom and 24 to $36 \mathrm{~h}$ after pathogen inoculation as controls for disease suppression. Oxytetracycline (Mycoshield, $200 \mu \mathrm{g} / \mathrm{ml}$ a.i.) (Novartis Crop Pro-

TABLE 1. Location, cultivar, treatment dates, and weather

\begin{tabular}{|c|c|c|c|c|c|c|c|c|c|}
\hline \multirow[b]{2}{*}{ Year, location } & \multirow[b]{2}{*}{ Cultivar } & \multicolumn{3}{|c|}{ Treatment dates } & \multicolumn{5}{|c|}{ Environmental conditions ${ }^{r}$} \\
\hline & & First $^{\mathrm{s}}$ & Second $^{t}$ & Pathogen $^{\mathrm{u}}$ & Temp. $\left({ }^{\circ} \mathrm{C}\right)^{\mathrm{v}}$ & Max. temp. $\left({ }^{\circ} \mathrm{C}\right)^{\mathrm{w}}$ & Degree-days ${ }^{x}$ & Rain/total ${ }^{\mathrm{y}}$ & Rain $(\mathrm{mm})^{\mathrm{z}}$ \\
\hline \multicolumn{10}{|l|}{1999} \\
\hline \multirow{2}{*}{ Corvallis } & Bartlett & 17 April & 19 April & 20 April & 10.0 & 16.2 & 72 & $5 / 13$ & 5 \\
\hline & Bosc & 20 April & 23 April & 24 April & 9.5 & 15.5 & 64 & $7 / 13$ & 14 \\
\hline $\begin{array}{l}\text { Medford } \\
2000\end{array}$ & Bartlett & 16 April & 18 April & 20 April & 12.2 & 19.4 & 102 & $1 / 12$ & 6 \\
\hline \multirow[t]{2}{*}{ Corvallis } & Bartlett & 10 April & 12 April & 13 April & 11.7 & 17.2 & 59 & $9 / 13$ & 26 \\
\hline & Bosc & 14 April & 17 April & 19 April & 10.2 & 15.0 & 54 & $8 / 12$ & 20 \\
\hline Medford & Bartlett & 4 April & 6 April & 7 April & 11.7 & 18.4 & 120 & $7 / 16$ & 94 \\
\hline
\end{tabular}

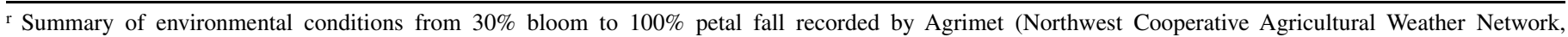
Bonneville Power Administration, and the U.S. Bureau of Reclamation, Boise, ID) weather stations located near the experimental field laboratories near Corvallis and Medford. Weather data can be accessed from the Agrimet website.

s Date of first application of bacterial antagonists, water, or antibiotics to trees in $30 \%$ bloom.

${ }^{t}$ Date of second application of bacterial antagonists, water, or antibiotics to trees in $70 \%$ bloom.

u Date of inoculation with Erwinia amylovora strain $153 \mathrm{~N}$ to trees in full bloom.

v Mean temperature.

${ }^{\mathrm{w}}$ Mean maximum temperature.

x Sum of degree-days (base $10^{\circ} \mathrm{C}$ ).

y Number of days with rain/total number of days.

$\mathrm{z}$ Total rainfall. 
tection, Greensboro, NC) also was included as a disease control treatment at $70 \%$ bloom and after pathogen inoculation in all trials except on Bosc pear, due to a limited number of trees.

At full bloom, trees were inoculated with $1 \times 10^{5}$ to $3 \times 10^{5}$ $\mathrm{CFU} / \mathrm{ml}$ suspensions of lyophilized cells of Ea153N (10) applied as a mist with a 100-liter tank of a motorized sprayer fitted with an agitator and a handgun at sunrise or after sunset under still wind conditions; spray volumes were 2 to 3 liters per tree, depending on tree size (Table 1).

Enumeration of bacterial populations on flowers. Six flowers with dehisced anthers were harvested from each replicate tree after application of bacterial antagonists and periodically during bloom until symptoms of fire blight were visible. The pistil and nectary were excised and placed in sterile $10 \mathrm{mM}$ potassium phosphate buffer, $\mathrm{pH}$ 7.1. Samples and dilutions were spread on Pseudomonas agar F (PAF; Difco Laboratories) for enumeration of Eh252, PAF containing kanamycin at $50 \mu \mathrm{g} / \mathrm{ml}$ for recovery of A506 aprX::Tn5, or PAF amended with rifampicin at $50 \mu \mathrm{g} / \mathrm{ml}$ for recovery of A506 and C9-1S. A506 and C9-1S were distinguished by colony morphology and color. Each medium contained cycloheximide at $50 \mu \mathrm{g} / \mathrm{ml}$ to inhibit growth of fungi and yeasts. CCT medium (4) containing nalidixic acid at $50 \mu \mathrm{g} / \mathrm{ml}$ was used for selective recovery of the pathogen. The detection limit was $1 \times 10^{2} \mathrm{CFU} /$ flower.

Disease assessment. Blossom clusters with symptoms of fire blight (necrosis, wilting, or bacterial ooze) were counted and removed immediately from trees over a 5-week period after symptoms were first visible. The cumulative number of fire blight infections (strikes) per tree was calculated.

Weather data. Weather data (Table 1) were obtained from AgriMet weather stations (Pacific Northwest Cooperative Agricultural Weather Network, Bonneville Power Administration, and the U.S. Bureau of Reclamation, Boise, ID) located within the Experimental Field laboratories near Corvallis and Medford. The data are available on the AgriMet website (http://www.usbr.gov/ pn/agrimet/).

Data analysis. Mean population size and standard error of bacterial strains on individual flowers were calculated by averaging the logarithm (base 10) of population values obtained on each sample date. Data are presented with a population size of $99 \mathrm{CFU}$ (detection limit - 1 CFU) assigned to individual flowers on which a strain was not detected. The incidence of detection of populations was recorded for each sampled tree at each time and the data were arcsine square root transformed before mean separation by Fisher's protected least significant difference (LSD) test at $P=0.05$ using the analysis of variance (ANOVA) procedure of SAS (Statistical Analysis Systems, Cary, NC).

To compare differences in growth of bacterial strains on flowers or to evaluate the effect of treatments on growth of the pathogen, the relative area under the population curve (RAUPC) was calculated for each tree in each trial. The area under the population curve (AUPC) was calculated for each trial with the following formula (26):

$$
A U P C=\sum_{i=1}^{n}\left[\left(y_{i}+y_{i}-1\right) / 2\right] \cdot\left(t_{i}-t_{i}-1\right)
$$

where $y$ is the mean population size of a bacterial strain on the $i$ th sample date and $t$ is the corresponding sample time. Because the length of the sample period varied among trials, the AUPC was converted to the RAUPC by dividing the AUPC by the elapsed number of days during the sampling period (26). The LSD at $P=$ 0.05 procedure was used to separate mean RAUPC values obtained for each bacterial treatment of each trial.

Intergeneric competition of bacterial antagonists was evaluated graphically with replacement series analysis and by ANOVA with the methods described by Wilson and Lindow (38) and Johnson et al. (8). For ANOVA, the enumerated populations of each antago- nist at petal fall were adjusted to the proportion of the bacterium in the initial inoculum by the equation $\log _{10}$ (population size) $\log _{10}$ (inoculum proportion). The strains were applied as a $1: 1$ mixture; therefore, the proportion of a strain in the inoculum was 0.5 . The mean adjusted populations were compared with mean populations achieved by single-strain inoculants by Fisher's protected LSD test at $P=0.05$.

The response of populations of antagonists to weather was evaluated with linear regression. Weather data were summarized from the day of first application of bacteria to $100 \%$ petal fall by calculating the sum of growing degree-days (base $10^{\circ} \mathrm{C}$ ) with the algorithm (maximum air temperature + minimum air temperature) $/ 2-10^{\circ} \mathrm{C}$ and the proportion of days with measurable rainfall for each trial (26). The interaction of environmental conditions with the RAUPC of the antagonists as single-strain inoculants and in combination by petal fall was evaluated graphically and with the REG procedure in SAS.

The number of diseased blossom clusters per tree was converted to a relative disease incidence by dividing the incidence of fire blight on treated trees by the incidence on the water-treated tree within each block. The relative disease incidence data were arcsine square root-transformed before analysis. Disease incidence data for trees treated with $\mathrm{C} 9-1 \mathrm{~S}$ alone and in combination were analyzed separately from trees treated with Eh252 alone and in combination. For analysis of individual and pooled experiments, Fisher's protected LSD test at $P=0.05$ was used to separate treatment means of the transformed relative disease incidence values.

\section{RESULTS}

Nutrient utilization and epiphytic fitness of A506 and A506 aprX::Tn5. The nutrient utilization profile of A506 was compared with the extracellular protease mutant A506 aprX::Tn5 using the Biolog PM system. The phenotype microarray results for strain A506 are presented in a companion article (27). Significant differences between the strains were observed in resistance of A506 aprX::Tn5 to kanamycin and reduced catabolism of the following di- and tripeptides by A506 aprX::Tn5 compared with the wild-type parental strain: Ala-Gln, Ala-Tyr, Arg-Phe, Arg-Tyr, His-Tyr, Leu-Asn, Leu-His, Pro-Arg, Tyr-Gln, Ala-Ala-Ala, Gly-Gly-Gly, Gly-Gly-Leu, Gly-Gly-lle, Gly-GlyPhe, and Tyr-Gly-Gly. Catabolism of carbohydrates reported on floral tissues of pear and apple (21) was not affected by the Tn5 mutation (data not shown).

A506 and A506 aprX::Tn5 were applied as single-strain inoculants at $1 \times 10^{8} \mathrm{CFU} / \mathrm{ml}$ to flowers twice during bloom and established mean populations of $2.2 \times 10^{5}$ to $4.3 \times 10^{6} \mathrm{CFU} /$ flower (Table 2). In all, 90 to $100 \%$ of flowers sampled had detectable populations of the applied antagonist. The RAUPC of A506 was similar to A506 aprX::Tn5 in three of six trials (Table 2). In one trial, the RAUPC of A506 was greater than A506 aprX::Tn5 and, in two trials, the AUPC of A506 aprX::Tn5 was significantly greater than the parental strain A506. Analysis of pooled trials did not reveal a significant difference in the RAUPC of A506 compared with the extracellular protease-deficient mutant (Table 2). The lack of production of the extracellular protease by A506 aprX::Tn5 did not decrease epiphytic fitness of this mutant on flowers.

Establishment of C9-1S and Eh252 on flowers. Eh252 and C9-1S established mean populations of $6.3 \times 10^{4}$ to $6.0 \times 10^{6}$ CFU/flower on 90 to $100 \%$ of sampled pear flowers (Table 2). In four of six trials, the RAUPC of C9-1S was similar to that of Eh252 (Table 2). In one trial, the RAUPC of C9-1S was significantly greater than Eh252 but, in another trial, the RAUPC of Eh252 was greater than that of C9-1S. Analysis of pooled trials did not reveal a significant difference in the RAUPC of Eh252 compared with C9-1S (Table 2). 
C9-1S populations in mixtures with $\mathbf{A 5 0 6}$ or $\mathbf{A 5 0 6}$ aprX::Tn5. The sum of the antagonist population attained by petal fall with the combination of C9-1S with A506 was significantly $(P=0.05)$ greater than at least one of the component strains of the mixture applied alone in three of six trials (Fig. 1C, E, and I). Populations of C9-1S and A506, adjusted for their proportion in the initial inoculum, on flowers treated with the 1:1 mixture of the two strains were compared by ANOVA to popu- lations established from the corresponding strain applied alone. The mean populations of A506 applied with C9-1S were not significantly different than mean populations of A506 applied as a single strain in four of six trials; in two of the six trials, A506 populations were significantly lower when applied in combination with C9-1S (Fig. 1A and G). In contrast, the mean population sizes of C9-1S when combined with A506 were significantly greater $(P=0.05)$ in five of six trials compared with populations

TABLE 2. Relative area under the population curve (RAUPC) of Pseudomonas fluorescens A506, the extracellular protease mutant A506 aprX::Tn5, Pantoea vagans $\mathrm{C} 9-1 \mathrm{~S}$, and Pantoea agglomerans Eh252 on pear flowers

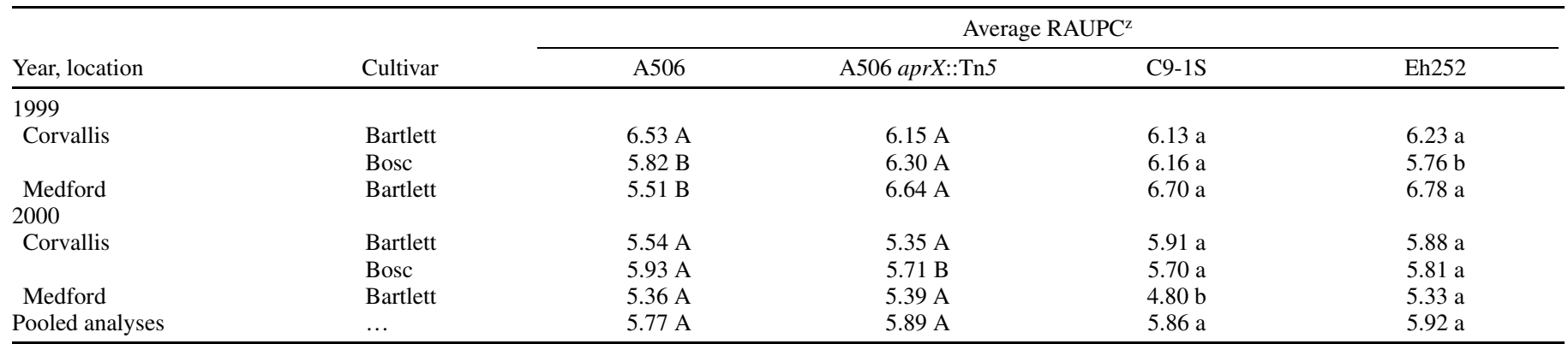

${ }^{z}$ Trees arranged in a complete randomized block design with four or five replications per treatment were sprayed twice with A506, A506 aprX::Tn5, C9-1S, or Eh252 at $1 \times 10^{8} \mathrm{CFU} / \mathrm{ml}$ at 30 and $70 \%$ bloom. The RAUPC of a bacterium was calculated from flowers during bloom. Mean RAUPC of A506 was compared with its extracellular protease-deficient mutant and values within a row with the same uppercase letter are not significantly different by Fisher's protected least significance difference at $P=0.05$. Similarly, the RAUPC of C9-1S and Eh252 were compared; values within a row followed by the same lowercase letter are not significantly different by Fisher's protected least significance difference at $P=0.05$.
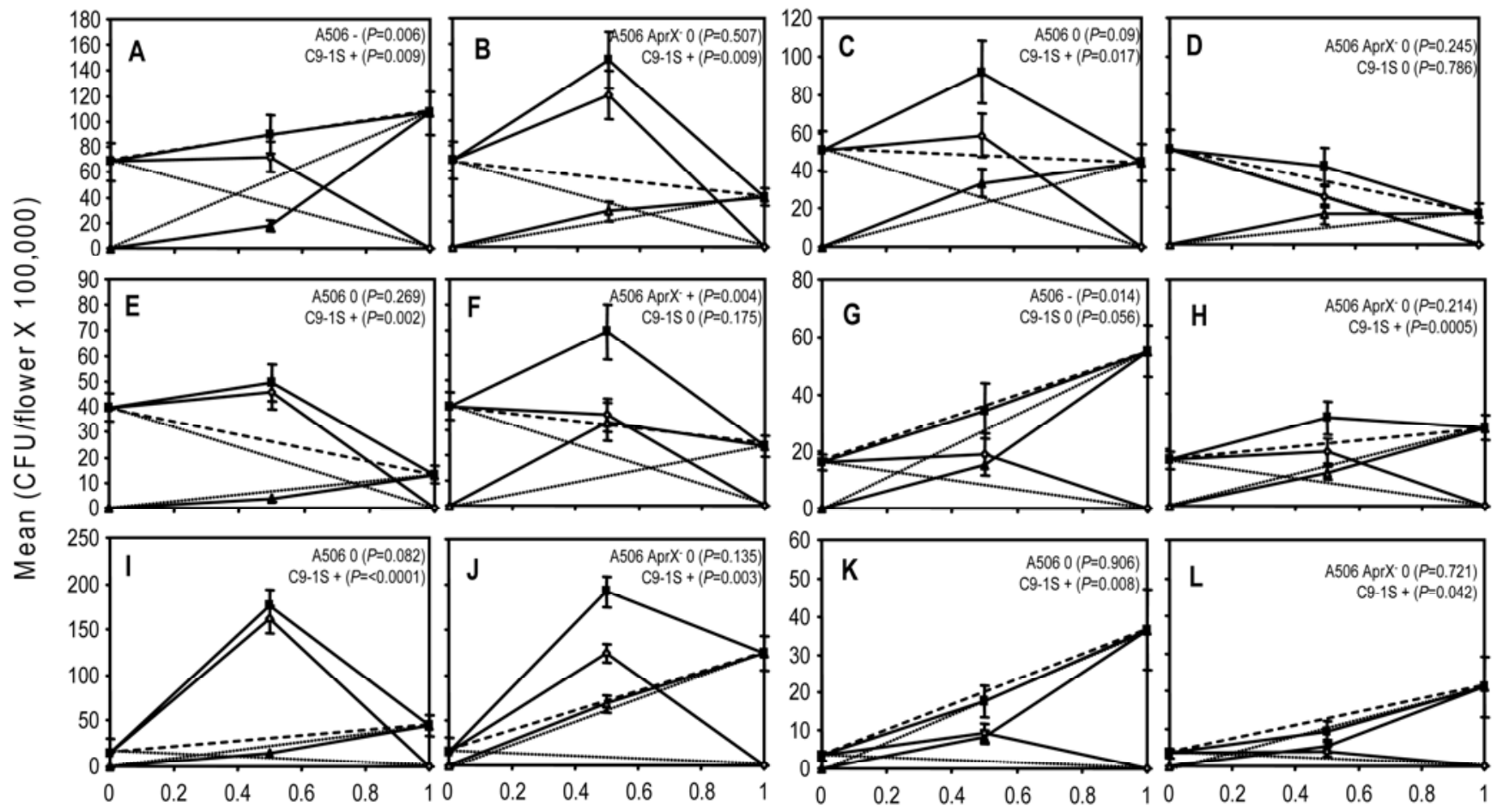

\section{Proportion of A506 or A506 aprX::Tn5 in inoculum 1-proportion of C9-1S in inoculum}

Fig. 1. Replacement series graphs depicting mean detectable population sizes (CFU $\times 100,000$ per flower) of Pantoea vagans strain C9-1S (open diamonds) and Pseudomonas fluorescens strain A506 (closed triangles) or the extracellular protease-deficient mutant A506 aprX::Tn5 (open triangles) on flowers sampled at petal fall on A and B, Bartlett pear, Corvallis 1999; C and D, Bartlett pear, Corvallis 2000; E and F, Bosc pear, Corvallis 1999; G and H, Bosc pear, Corvallis 2000; I and J, Bartlett pear, Medford 1999; and $\mathbf{K}$ and $\mathbf{L}$, Bartlett pear, Medford 2000. Filled squares represent the sum of antagonist populations applied as single-strain inoculants or in combination. Dotted lines represent the expected population size of each strain and dashed lines the sum of two strains if interstrain competition is equivalent to intrastrain competition. Text in each panel provides the $P$ value from analysis of variance comparison of mean adjusted population size of a strain applied in mixed inoculum to the measured mean population size of the same strain applied alone. Symbols after the strain name: "+" indicates that the population size of a strain applied in combination was significantly greater than the population size of the same strain applied alone, " 0 " indicates no significant difference between populations of a strain applied in combination and as a single-strain inoculant, and "-" indicates a significant decrease between the population size of a strain applied in combination and the population achieved by the strain applied alone. 
established by $\mathrm{C} 9-1 \mathrm{~S}$ applied alone; in the one remaining trial, the populations of C9-1S were not significantly different when applied alone or in combination with A506 (Fig. 1G).

When C9-1S was combined with A506 aprX::Tn5, the total antagonist population was significantly $(P=0.05)$ greater than individual strains applied alone in four of six trials (Fig. 1B, F, J, and $\mathrm{H}$ ). The adjusted mean populations of A506 aprX::Tn5 applied with C9-1S were not significantly different than the mean populations of A506 aprX::Tn5 applied as a single strain in five of six trials (Fig. 1). In one trial, A506 aprX::Tn5 populations were significantly greater when applied with C9-1S (Fig. 1F). The adjusted mean population sizes of $\mathrm{C} 9-1 \mathrm{~S}$ when combined with A506 aprX::Tn5 were significantly greater in four of six trials (Fig. 1B, H, J, and L) compared with populations established by C9-1S applied alone. This result is similar to the observed increased populations of C9-1S when combined with A506.

Comparing the sum of antagonist populations attained by petal fall with a combination of C9-1S with A506 to the combination of C9-1S with A506 aprX::Tn5 revealed no significant difference $(P=0.05)$ in the mean total antagonist population in five of six trials. In one trial, the total antagonist population of C9-1S with A506 (Fig. 1C) was significantly greater $(P=0.0054)$ than populations of C9-1S with A506 aprX::Tn5 (Fig. 1D).

Eh252 populations in mixtures with A506 or $\mathbf{A 5 0 6}$ aprX::Tn5. The sum of the antagonist population attained by petal fall with combination of Eh252 with A506 was significantly $(P=0.05)$ greater than at least one of the component strains of the mixture applied alone in three of six trials (Fig. 2E, G, and I). The mean adjusted populations of A506 were typically lower when applied with Eh252 than when applied as a single strain (Fig. 2), with significant differences observed in three trials (Fig. 2A, C, and $\mathrm{G})$. The mean adjusted population sizes of Eh252 when combined with A506 were significantly greater compared with populations established by Eh252 alone in four of the six trials (Fig. $2 \mathrm{E}, \mathrm{G}, \mathrm{I}$, and $\mathrm{K}$ ). This observation with Eh252 is similar to the increased populations of C9-1S when combined with A506.

Combining Eh252 with A506 aprX::Tn5 resulted in a significantly $(P=0.05)$ greater total antagonist population size than populations established by Eh252 or A506 aprX::Tn5 applied alone in four of six trials (Fig. 2D, F, H, and J). The mean adjusted populations of A506 aprX::Tn5 applied with Eh252 were not significantly different than mean populations of A506 aprX::Tn5 applied as a single-strain inoculant in any of the trials (Fig. 2). The mean adjusted population sizes of Eh252 on flowers when combined with A506 aprX::Tn5 were significantly greater than populations established by Eh252 applied alone in four of six trials (Fig. 2D, F, H, and J).

The mean total antagonist populations attained by petal fall with combination of Eh252 with A506 were not significantly different $(P=0.05)$ than total antagonist populations established by Eh252 with A506 aprX::Tn5 in five of six trials. In one trial, the total antagonist population of Eh252 with A506 was significantly $(P=0.018)$ greater than the total antagonist population of Eh252 with A506 aprX::Tn5 (Fig. 2A and B).

Comparisons of total population sizes of antagonists applied as mixtures. Overall, the mean total antagonist population size of the combination of Eh252 with A506 was not significantly different $(P=0.05)$ than that of the combination of C9-1S with A506 in four of six trials. In one trial (Fig. 2K), treatment of trees with Eh252 and A506 resulted in significantly
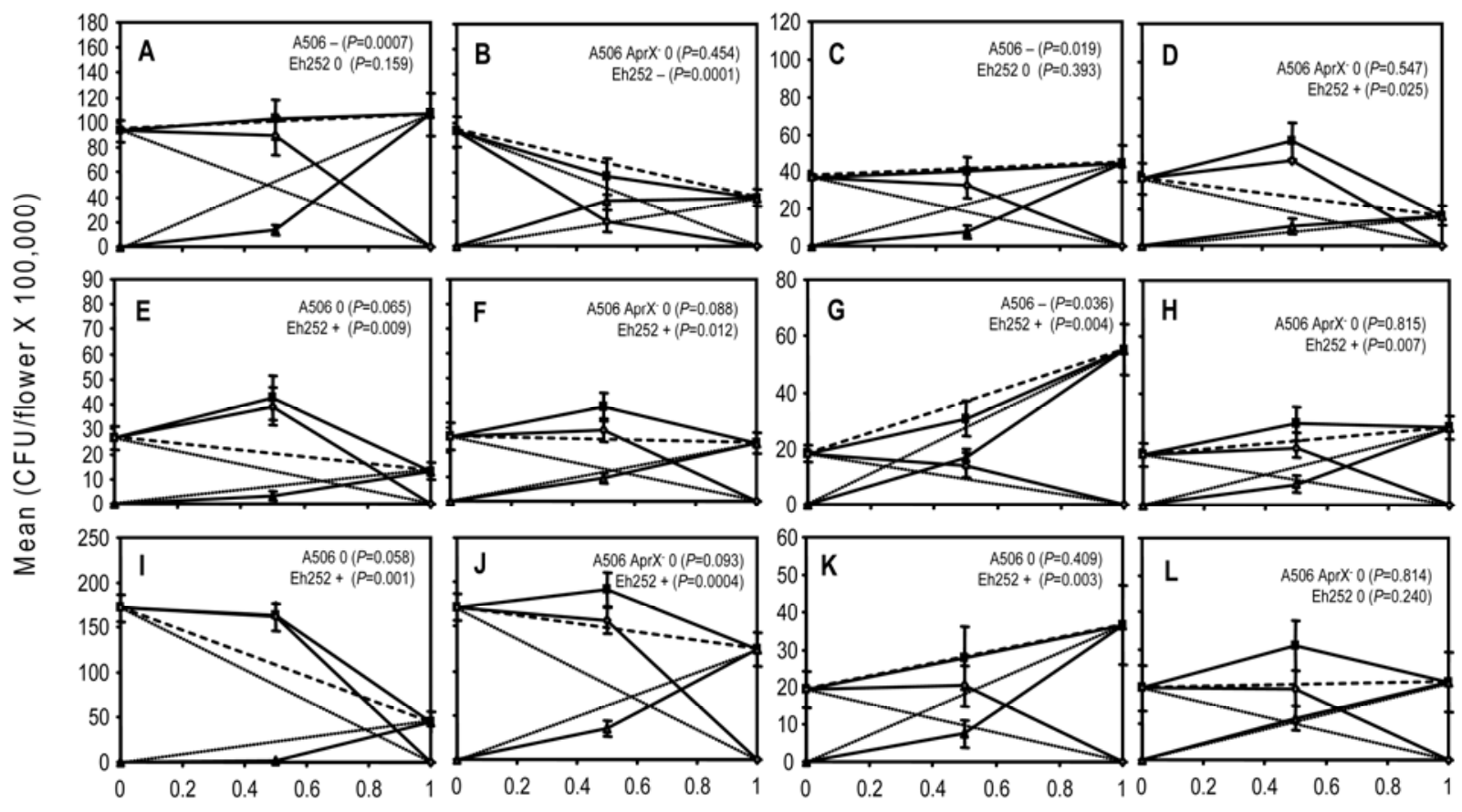

\section{Proportion of A506 or A506 aprX::Tn5 in inoculum 1-proportion of Eh252 in inoculum}

Fig. 2. Replacement series graphs depicting mean detectable population sizes (CFU $\times 100,000$ per flower) of Pantoea agglomerans strain Eh252 (open diamonds) and Pseudomonas fluorescens strain A506 (closed triangles) or the extracellular protease-deficient mutant A506 aprX::Tn5 (open triangles) on flowers sampled at petal fall on A and B, Bartlett pear, Corvallis 1999; C and D, Bartlett pear, Corvallis 2000; E and F, Bosc pear, Corvallis 1999; G and H, Bosc pear, Corvallis 2000; I and J, Bartlett pear, Medford 1999; and K and L, Bartlett pear, Medford 2000. Filled squares represent the sum of antagonist populations applied as single-strain inoculants or in combination. Dotted lines represent the expected population size of each strain and dashed lines the sum of two strains if interstrain competition is equivalent to intrastrain competition. Text in each panel provides the $P$ value from analysis of variance comparison of mean adjusted population size of a strain applied in mixed inoculum to the measured mean population size of the same strain applied alone. Symbols after the strain name: "+" indicates that the population size of a strain applied in combination was significantly greater than the population size of the same strain applied alone, "0" indicates no significant difference between populations of a strain applied in combination and as a single-strain inoculant, and "-" indicates a significant decrease between the population size of a strain applied in combination and the population achieved by the strain applied alone. 
$(P=0.045)$ greater populations than with application of $\mathrm{C} 9-1 \mathrm{~S}$ with A506 (Fig. 1K) but the reverse was observed in another trial $(P=0.011)$ (Figs. 1C and 2C).

Similarly, the mean total antagonist population size of the combination of Eh252 with A506 aprX::Tn5 was not significantly different $(P=0.05)$ than that of the combination of C9-1S with A506 aprX::Tn5 in five of six trials. The exception was in one trial (Fig. 1B), when treatment with C9-1S with A506 aprX::Tn5 resulted in significantly $(P=0.0016)$ greater populations than that of Eh252 with A506 aprX::Tn5 (Fig. 2B).

Influence of weather on growth of antagonists on flowers. Analysis of weather during bloom among trials revealed a significant $(P=0.0009)$ linear relationship between incidence of days with rain $(y)$ and accumulated degree-days $(x)(y=-84.283 x$ $\left.+107.84 ; r^{2}=0.98\right)$, meaning that an increase in the number of rainy days corresponded to cooler temperatures and lower accumulated degree-day values. This relationship was supported if conditions for the Bartlett pear plot in Medford 2000 were excluded from the data set; inclusion of those conditions resulted in no significant $(P=0.11)$ correlation between incidence of rainy days with accumulated degree-days. The weather in Medford 2000 during pear bloom was distinct compared with the other research orchards: a combination of warm weather $\left(18^{\circ} \mathrm{C}\right.$ mean maximum daily temperature) and 6 days with $>10 \mathrm{~mm}$ rainfall per $24-\mathrm{h}$ period during the 16-day bloom period. None of the other plots were exposed to rainfall exceeding $8.5 \mathrm{~mm}$ over a 24-h period. The RAUPC of bacterial strains in the Medford 2000 trial was lower than expected based on accumulated degree-days during bloom.

Excluding the Medford 2000 trial from the dataset revealed a significant $(P \leq 0.05)$ positive correlation between warmer temperatures (accumulated degree-days, base $10^{\circ} \mathrm{C}$ ) and higher RAUPC with each bacterial treatment (Fig. 3), except A506 applied alone $(P=0.91)$ (Fig. 3A). Correspondingly, a significant $(P \leq 0.05)$ negative correlation was observed between the incidence of rainy days and RAUPC for each bacterial treatment when the Medford 2000 trial was excluded, except for A506 $(P=$ $0.97)$ (Fig. 3B) and Eh252 mixed with A506 aprX::Tn5 $(P=0.06)$ (Fig. 3O). Bloom periods with fewer days with measurable rainfall were associated with greater population sizes of bacteria established on flowers (Fig. 3).

Populations of Ea153N on pear flowers. Population sizes of Ea153N on flowers were generally near or below the limit of detection $\left(1 \times 10^{2} \mathrm{CFU} /\right.$ flower $)$ on samples taken within 4 days

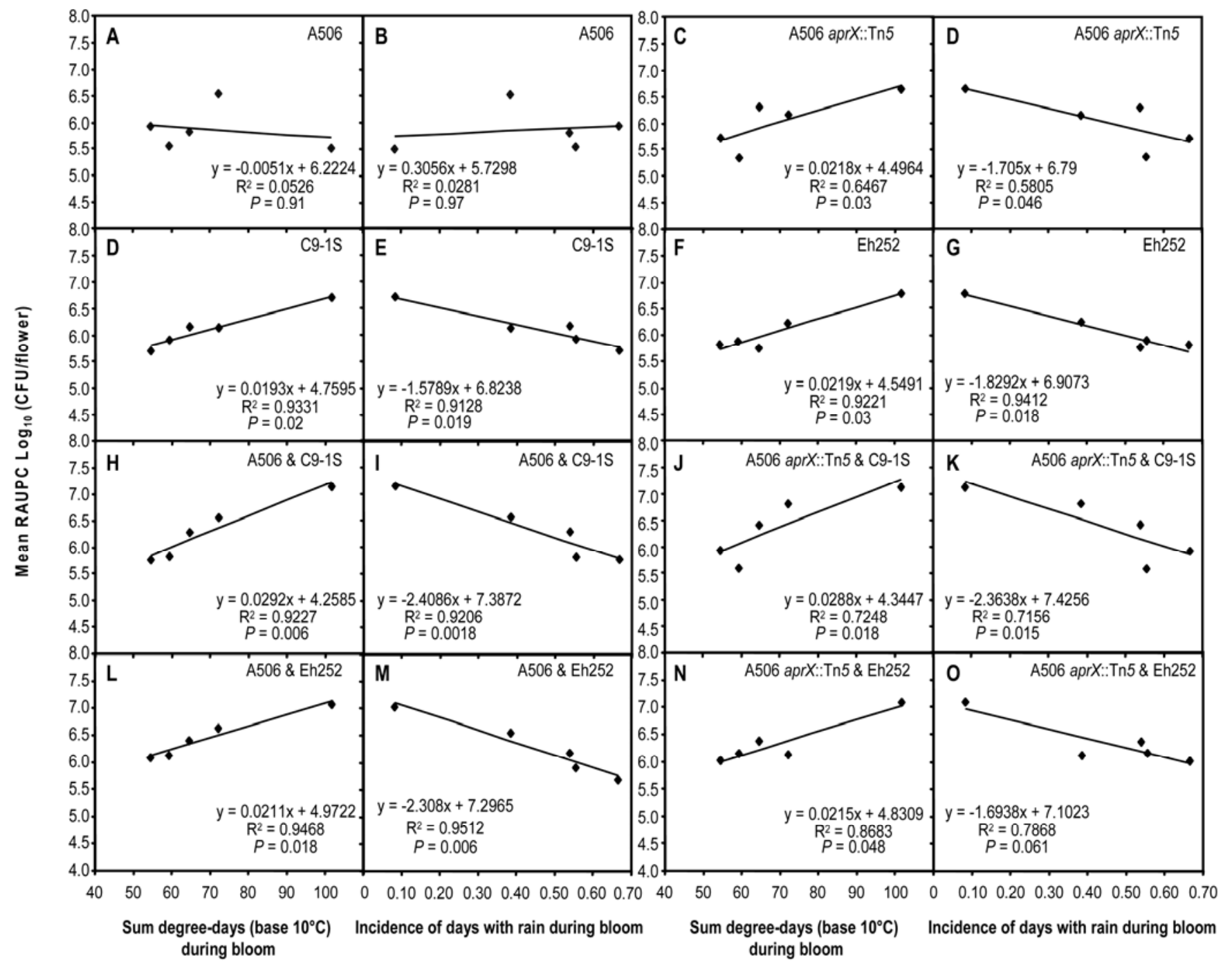

Fig. 3. Influence of environmental conditions on populations of bacterial antagonists on pear flowers. Mean relative area under the population curve (RAUPC) for total populations of the bacterial antagonists applied as single-strain inoculants and in combination from each pear trial regressed on A, C, D, F, H, J, L, and $\mathbf{N}$, sum degree-days during bloom (base $10^{\circ} \mathrm{C}$ ) and $\mathbf{B}, \mathbf{D}, \mathbf{E}, \mathbf{G}, \mathbf{I}, \mathbf{K}, \mathbf{M}$, and $\mathbf{O}$, proportion of days with rain during bloom. Strain treatments are indicated on each graph. Weather in each trial was summarized from time of first application at 30\% bloom to the sample date of 100\% petal fall. Weather and population data from the Bartlett pear trial in Medford in 2000 was excluded from this analysis. The solid regression line is presented on each graph along with the model formula, regression coefficient, and $P$ value. 
after pathogen inoculation (data not shown). By petal fall, however, 28 to $83 \%$ of water-treated flowers had detectable populations of the pathogen, indicating growth of Ea153N on floral tissues over the bloom period (Table 3 ). The exception was that the pathogen was not recovered from samples of Bartlett pear in Medford 2000, where $13 \mathrm{~mm}$ of rain fell the day after inoculation. The RAUPC of Ea153N was 2.2 to 3.9 on water-treated trees (Table 3).

Compared with water-treated controls, A506 and its extracellular protease-deficient mutant significantly decreased the incidence of establishment of detectable populations of Ea153N on flowers in only one (Bosc 2000) of five trials (Table 3). In two trials (Bartlett and Bosc 1999), the incidence of detectable populations of Ea153N on A506- or A506 aprX::Tn5-treated trees was significantly greater compared with water-treated trees (Table 3 ). The RAUPC of the pathogen on A506- or A506 aprX::Tn5treated trees was significantly decreased compared with watertreated trees in two of five trials (Bartlett 1999 and Bosc 2000, Table 3). In one trial (Bosc 1999), the RAUPC of Ea153N was significantly greater on A506-treated trees compared with watertreated trees (Table 3).

C9-1S significantly decreased the incidence of detectable populations of Ea $153 \mathrm{~N}$ on flowers compared with water-treated controls in four of five trials (Table 3). Treatment of trees with C9-1S mixed with A506 resulted in a significant decrease in the incidence of detectable pathogen populations compared with watertreated controls in only two of five trials (Table 3 ). The incidence of recovery of detectable populations of the pathogen on trees treated with C9-1S combined with A506 aprX::Tn5 was significantly decreased compared with water treatment in three of five trials (Table 3). The RAUPC of the pathogen on trees treated with C9-1S alone, C9-1S combined with A506, or C9-1S mixed with A506 aprX::Tn5 was significantly decreased compared with water-treated trees in three of five trials (Table 3 ).

Like C9-1S, Eh252 significantly decreased the incidence of detection of Ea153N on flowers compared with water-treated controls in four of five trials (Table 3). Trees treated with Eh252 mixed with A506 or Eh252 combined with A506 aprX::Tn5 resulted in a significant decrease in the incidence detection of the pathogen compared with water-treated trees in two of five trials (Table 3). The RAUPC of the pathogen on trees treated with Eh252 alone or Eh252 mixed with A506 aprX::Tn5 was significantly decreased compared with water-treated trees in four of five trials (Table 3). On trees treated with Eh252 combined with A506, the RAUPC of the pathogen was significantly reduced compared with water-treated trees in three of five trials (Table 3).

Suppression of fire blight. Symptoms of fire blight were observed in five of six experimental plots (Table 4); symptoms were not observed on Bartlett pear in Medford 2000. The mean number of diseased blossom clusters on inoculated, water-treated trees varied among trials from a low of 29 strikes per tree on Bosc in 1999 to a high of 204 strikes per tree on Bosc in 2000 (Table 4). A pre- and postinoculation treatment with oxytetracycline significantly reduced the incidence of fire blight compared with water-treated controls by an average of $39 \%$ in the three trials in which the product was tested (Table 4). Streptomycin provided excellent control of fire blight in these trials, which were inoculated with a streptomycin-sensitive strain of the pathogen. Streptomycin reduced the incidence of fire blight by an average of $81 \%$ compared with water-treated controls (Table 4).

A506 significantly reduced the incidence of fire blight compared with water treatment in three of five trials (Table 4). When evaluated among all trials, however, A506 did not significantly reduce the disease incidence compared with water treatment.

The extracellular protease-deficient mutant A506 aprX::Tn5 significantly reduced the incidence of fire blight by $41 \%$ compared with water-treated controls among all trials (Table 4). A506 aprX::Tn5 provided better control than the parental strain A506 in four of five trials but a significant difference in efficacy of the two strains was not observed when all trials were considered together (Table 4).

Treatment of trees with $\mathrm{C} 9-1 \mathrm{~S}$ significantly reduced the incidence of fire blight by an average of $42 \% \quad(P=0.05)$ compared with water-treated trees (Table 4). The level of disease suppression by C9-1S was similar to that provided by A506 aprX::Tn5 in two trials and better in two of five trials (Table 4). When evaluated among all trials, C9-1S was similar to oxytetracycline and A506 aprX::Tn5 but not as effective as strep-

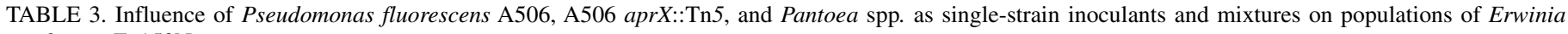
amylovora Ea153N

\begin{tabular}{|c|c|c|c|c|c|c|c|c|c|c|}
\hline \multirow[b]{2}{*}{ Year, location } & \multirow[b]{2}{*}{ Cultivar } & \multicolumn{9}{|c|}{ Average relative area under the population curve (RAUPC) and incidence of detection of Ea153N per treatment ${ }^{\mathrm{u}}$} \\
\hline & & Water & A506 & $\operatorname{Tn} 5^{\mathrm{v}}$ & C9-1S & C9 \& $\mathrm{A}^{\mathrm{w}}$ & C9 \& $\operatorname{Tn} 5^{x}$ & Eh252 & $\mathrm{Eh} \& \mathrm{~A}^{\mathrm{y}}$ & Eh $\& \operatorname{Tn} 5^{z}$ \\
\hline \multicolumn{11}{|l|}{1999} \\
\hline \multirow[t]{2}{*}{ Corvallis } & Bartlett & $\begin{array}{c}3.94 \mathrm{~A} \\
(0.33 \mathrm{~B})\end{array}$ & $\begin{array}{c}3.10 \mathrm{~B} \\
(0.75 \mathrm{~A})\end{array}$ & $\begin{array}{c}3.21 \mathrm{~B} \\
(0.71 \mathrm{~A})\end{array}$ & $\begin{array}{c}2.50 \mathrm{C} \\
(0.00 \mathrm{C})\end{array}$ & $\begin{array}{c}2.80 \mathrm{~B} \\
(0.25 \mathrm{~B})\end{array}$ & $\begin{array}{c}2.48 \mathrm{C} \\
(0.29 \mathrm{~B})\end{array}$ & $\begin{array}{c}2.91 \mathrm{~B} \\
(0.12 \mathrm{C})\end{array}$ & $\begin{array}{c}2.69 \mathrm{~B} \\
(0.46 \mathrm{AB})\end{array}$ & $\begin{array}{l}2.71 \mathrm{~B} \\
(0.46 \mathrm{AB})\end{array}$ \\
\hline & Bosc & $\begin{array}{c}2.19 \mathrm{BC} \\
(0.28 \mathrm{BC})\end{array}$ & $\begin{array}{c}2.34 \mathrm{~A} \\
(0.68 \mathrm{~A})\end{array}$ & $\begin{array}{l}2.29 \mathrm{AB} \\
(0.68 \mathrm{~A})\end{array}$ & $\begin{array}{c}2.10 \mathrm{C} \\
(0.16 \mathrm{C})\end{array}$ & $\begin{array}{c}2.17 \mathrm{BC} \\
(0.28 \mathrm{BC})\end{array}$ & $\begin{array}{l}2.07 \mathrm{C} \\
(0.48 \mathrm{AB})\end{array}$ & $\begin{array}{l}2.23 \mathrm{AB} \\
(0.32 \mathrm{~B})\end{array}$ & $\begin{array}{l}2.14 \mathrm{BC} \\
(0.32 \mathrm{~B})\end{array}$ & $\begin{array}{l}2.03 \mathrm{C} \\
(0.44 \mathrm{AB})\end{array}$ \\
\hline Medford & Bartlett & $\begin{array}{c}3.33 \mathrm{~A} \\
(0.58 \mathrm{~A})\end{array}$ & $\begin{array}{c}3.20 \mathrm{~A} \\
(0.54 \mathrm{~A})\end{array}$ & $\begin{array}{l}2.77 \mathrm{AB} \\
(0.46 \mathrm{~A})\end{array}$ & $\begin{array}{c}2.34 \mathrm{~B} \\
(0.04 \mathrm{C})\end{array}$ & $\begin{array}{c}2.28 \mathrm{~B} \\
(0.17 \mathrm{~B})\end{array}$ & $\begin{array}{l}2.27 \mathrm{~B} \\
(0.25 \mathrm{~B})\end{array}$ & $\begin{array}{c}2.02 \mathrm{C} \\
(0.00 \mathrm{C})\end{array}$ & $\begin{array}{l}2.16 \mathrm{BC} \\
(0.08 \mathrm{C})\end{array}$ & $\begin{array}{l}2.27 \mathrm{~B} \\
(0.04 \mathrm{C})\end{array}$ \\
\hline \multicolumn{11}{|l|}{2000} \\
\hline \multirow[t]{2}{*}{ Corvallis } & Bartlett & $\begin{array}{c}2.96 \mathrm{~A} \\
(0.47 \mathrm{~A})\end{array}$ & $\begin{array}{l}2.88 \mathrm{AB} \\
(0.47 \mathrm{~A})\end{array}$ & $\begin{array}{c}2.51 \mathrm{~B} \\
(0.47 \mathrm{~A})\end{array}$ & $\begin{array}{l}2.57 \mathrm{AB} \\
(0.10 \mathrm{~B})\end{array}$ & $\begin{array}{c}2.58 \mathrm{AB} \\
(0.23 \mathrm{AB})\end{array}$ & $\begin{array}{l}2.59 \mathrm{AB} \\
(0.13 \mathrm{~B})\end{array}$ & $\begin{array}{c}2.38 \mathrm{~B} \\
(0.07 \mathrm{~B})\end{array}$ & $\begin{array}{c}2.61 \mathrm{AB} \\
(0.23 \mathrm{AB})\end{array}$ & $\begin{array}{l}2.48 \mathrm{~B} \\
(0.23 \mathrm{AB})\end{array}$ \\
\hline & Bosc & $\begin{array}{c}3.24 \mathrm{~A} \\
(0.83 \mathrm{~A})\end{array}$ & $\begin{array}{l}2.35 \mathrm{BC} \\
(0.53 \mathrm{~B})\end{array}$ & $\begin{array}{l}2.58 \mathrm{~B} \\
(0.47 \mathrm{BC})\end{array}$ & $\begin{array}{l}2.49 \mathrm{~B} \\
(0.30 \mathrm{CD})\end{array}$ & $\begin{array}{c}2.26 \mathrm{C} \\
(0.17 \mathrm{D})\end{array}$ & $\begin{array}{l}2.48 \mathrm{~B} \\
(0.23 \mathrm{CD})\end{array}$ & $\begin{array}{l}2.33 \mathrm{BC} \\
(0.33 \mathrm{C})\end{array}$ & $\begin{array}{c}2.73 \mathrm{~B} \\
(0.63 \mathrm{~B})\end{array}$ & $\begin{array}{c}2.26 \mathrm{C} \\
(0.33 \mathrm{C})\end{array}$ \\
\hline
\end{tabular}

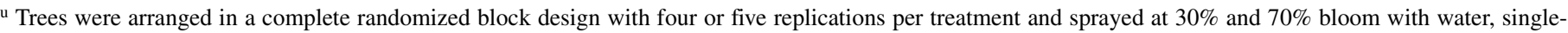
strain inoculants $\left(1 \times 10^{8} \mathrm{CFU} / \mathrm{ml}\right)$, or two-strain mixtures with each strain at $5 \times 10^{7} \mathrm{CFU} / \mathrm{ml}$. At full bloom, the pathogen Ea153N was applied at $3 \times 10^{5}$ $\mathrm{CFU} / \mathrm{ml}$. Average RAUPC during late bloom was calculated from mean populations of Ea153N in the final three samples taken during the bloom period. Mean incidence of populations of Ea153N $\geq 1 \times 10^{2} \mathrm{CFU} /$ flower (the detection limit) was calculated by determining the fraction of flowers with detectable populations of Ea153N on individual flowers during late bloom. Mean RAUPC within a row followed by the same uppercase letter are not significantly different by Fisher's protected least significance difference at $P=0.05$. Mean incidence of populations of Ea $153 \mathrm{~N} \geq 1 \times 10^{2} \mathrm{CFU} / \mathrm{flower}$ in parentheses within a row followed by the same letter are not significantly different by Fisher's protected least significance difference on the arc-sine square root transformed population incidence data at $P=0.05$.

v A506 aprX::Tn5.

${ }^{\mathrm{w}} \mathrm{C} 9-1 \mathrm{~S}$ and A506.

${ }^{x}$ C9-1S and A506 aprX::Tn5.

y Eh252 and A506.

${ }^{\text {z }}$ Eh252 and A506 aprX::Tn5.
} 
tomycin in suppressing disease caused by the streptomycinsensitive strain Ea153N.

Combining C9-1S with A506 gave variable results in disease control. The suppression of fire blight with C9-1S mixed with A506 was 10 to $74 \%$, with a mean of $44 \%$ among trials (Table 4 ). In three trials, C9-1S mixed with A506 provided control of fire blight similar to C9-1S alone; in a second trial (Bosc 1999), the mixture provided significantly less control than C9-1S alone; and, in a third trial (Bartlett 2000), the combination was superior to C9-1S alone (Table 4).

Disease control with C9-1S mixed with A506 aprX::Tn5 was 57 to $74 \%$ and was less variable than treatment with C9-1S combined with the parental strain A506. In two trials (Medford 1999 and Bartlett 2000), C9-1S mixed with A506 aprX::Tn5 provided significantly better disease control than single-strain inoculants or C9-1S mixed with A506 (Table 4). In three other trials, treatment with C9-1S mixed with A506 aprX::Tn5 resulted in disease levels similar to those of treatment with single-strain inoculants of C9-1S or A506 aprX::Tn5 (Table 4). Considering all trials, the combination of $\mathrm{C} 9-1 \mathrm{~S}$ with $\mathrm{A} 506$ aprX::Tn5 reduced the incidence of fire blight by $68 \%$, which was significantly $(P=$ $0.05)$ better than single-strain inoculants or the combination of C9-1S with A506 (Table 4).

Treatment with Eh252 significantly reduced the incidence of fire blight compared with water-treated trees in four of five trials (Table 4). Control by Eh252 was 18 to $88 \%$, with a mean of $55 \%$ among trials (Table 4). Considering all trials, the level of disease control by Eh252 was not significantly different than with treatment with C9-1S at $P=0.05$ but Eh252 was more variable than $\mathrm{C} 9-1 \mathrm{~S}$ in disease suppression.

Combining Eh252 with A506 resulted in levels of disease suppression similar to those of Eh252 alone in each trial (Table 4). Combining Eh252 with A506 did not improve the variability in disease suppression that was observed with the individual strains; the combination resulted in 28 to $74 \%$ reduction in the incidence of fire blight strikes compared with water-treated trees (Table 4). Considering all trials, Eh252 combined with A506 significantly reduced the incidence of fire blight by $59 \%$ compared with water-treated controls (Table 4).

Treatment with the combination of Eh252 with A506 aprX::Tn5 provided more consistent levels of disease control (46 to $86 \%$ ) than Eh252 as a single-strain inoculant or the combination of
Eh252 with A506 (Table 4). In two of five trials (Bartlett and Bosc 1999), Eh252 mixed with A506 aprX::Tn5 significantly reduced the incidence of fire blight compared with Eh252 or Eh252 mixed with A506 (Table 4). Considering all trials, Eh252 mixed with A506 aprX::Tn5 reduced the incidence of fire blight strikes by $71 \%$ compared with water-treated controls. The disease control by Eh252 mixed with A506 aprX::Tn5 exceeded the control provided by oxytetracycline and was similar to the level of control attained by streptomycin (Table 4 ).

\section{DISCUSSION}

In this study, we demonstrated that mechanistic compatibility is an important factor determining the consistent efficacy of mixtures of bacterial antagonists for biological control of plant disease. Mixtures of bacterial antagonists designed to be mechanistically compatible afforded significantly better control, with less variation in efficacy, than single-strain inoculants or mechanistically incompatible mixtures. The importance of mechanistic compatibility was demonstrated with two strains of Pantoea spp. combined with A506 or A506 aprX::Tn5, a mutant of A506 deficient in production of an extracellular metalloprotease. A506 degrades a peptide antibiotic produced by both Eh252 and C9-1, whereas A506 aprX::Tn5 does not degrade the antibiotic (1). Because the peptide antibiotic is a key contributor to biological control of fire blight by Eh252 (26), its degradation is expected to diminish biocontrol efficacy. If the extracellular protease is produced by A506 on floral surfaces, it can degrade the Pantocin A-like antibiotic produced by Pantoea spp. and, in the absence of antibiosis; the pathogen can multiply and infect the host. The enhanced efficacies of the Pantoea spp.-A506 aprX::Tn5 mixtures observed in this study relative to Pantoea spp.-A506 mixtures are consistent with that scenario and can be attributed to conservation of antibiosis as a mechanism of suppression of $E$. amylovora by the Pantoea spp. It is possible that the enhanced biological control of these mixtures is due to the additive effects of Pantoea spp. combined with a slightly more efficacious derivative of A506. This possibility is not strongly supported because statistically significant differences in efficacy of A506 and A506 aprX::Tn5 were not observed when considering all of the field trials in this study. The mixtures of mechanistically compatible biocontrol strains (Pantoea spp.-A506 aprX::Tn5) provided statis-

TABLE 4. Relative incidence of fire blight on trees treated with water, bacterial antagonists alone or as mixtures, or commercial antibiotics

\begin{tabular}{|c|c|c|c|c|c|c|}
\hline \multirow[b]{3}{*}{ Treatment $^{\mathrm{y}}$} & \multicolumn{5}{|c|}{ Year, cultivar, and location ${ }^{z}$} & \multirow[b]{3}{*}{ Pooled data } \\
\hline & \multicolumn{3}{|c|}{1999} & \multicolumn{2}{|c|}{2000} & \\
\hline & Bartlett & Bosc & Medford & Bartlett & Bosc & \\
\hline Water & $1.00 \mathrm{~A}, \mathrm{a}(160)$ & 1.00 A,a (29) & $1.00 \mathrm{~A}, \mathrm{a}(63)$ & $1.00 \mathrm{~A}, \mathrm{a}(166)$ & $1.00 \mathrm{~A}, \mathrm{a}(204)$ & $1.00 \mathrm{~A}, \mathrm{a}$ \\
\hline A506 & $0.73 \mathrm{~B}, \mathrm{~b}$ & $1.10 \mathrm{~A}, \mathrm{a}$ & $0.92 \mathrm{AB}, \mathrm{ab}$ & $0.74 \mathrm{~B}, \mathrm{~b}$ & $0.74 \mathrm{~B}, \mathrm{~b}$ & $0.84 \mathrm{AB}, \mathrm{ab}$ \\
\hline A506 aprX::Tn5 & $0.71 \mathrm{~B}, \mathrm{~b}$ & $0.84 \mathrm{~B}, \mathrm{~b}$ & $0.39 \mathrm{C}, \mathrm{cd}$ & $0.50 \mathrm{C}, \mathrm{c}$ & $0.48 \mathrm{C}, \mathrm{c}$ & $0.59 \mathrm{BC}, \mathrm{bc}$ \\
\hline C9-1S & $0.44 \mathrm{BC}$ & $0.53 \mathrm{C}$ & $0.40 \mathrm{C}$ & $0.75 \mathrm{~B}$ & $0.78 \mathrm{~B}$ & $0.58 \mathrm{BC}$ \\
\hline C9-1S \& A506 & $0.26 \mathrm{C}$ & $0.90 \mathrm{AB}$ & $0.56 \mathrm{BC}$ & $0.50 \mathrm{C}$ & $0.56 \mathrm{BC}$ & $0.56 \mathrm{BC}$ \\
\hline C9-1S \& A506 aprX::Tn5 & $0.26 \mathrm{C}$ & $0.43 \mathrm{C}$ & $0.18 \mathrm{D}$ & $0.31 \mathrm{D}$ & $0.41 \mathrm{C}$ & $0.32 \mathrm{D}$ \\
\hline Eh252 & $0.36 \mathrm{c}$ & $0.88 \mathrm{ab}$ & $0.12 \mathrm{ef}$ & $0.59 \mathrm{bc}$ & $0.51 \mathrm{c}$ & $0.45 \mathrm{c}$ \\
\hline Eh252 \& A506 & $0.31 \mathrm{c}$ & $0.72 \mathrm{bc}$ & $0.26 \mathrm{de}$ & $0.34 \mathrm{~cd}$ & $0.63 \mathrm{bc}$ & $0.41 \mathrm{c}$ \\
\hline Eh252 \& A506 aprX::Tn5 & $0.14 \mathrm{~d}$ & $0.33 \mathrm{~d}$ & 0.16 ef & $0.29 \mathrm{~cd}$ & $0.54 \mathrm{c}$ & $0.29 \mathrm{de}$ \\
\hline Oxytetracycline & $0.51 \mathrm{~B}, \mathrm{~b}$ & NT & $0.62 \mathrm{BC}, \mathrm{c}$ & $0.69 \mathrm{~B}, \mathrm{~b}$ & NT & $0.61 \mathrm{BC}, \mathrm{bc}$ \\
\hline Streptomycin & $0.12 \mathrm{D}, \mathrm{d}$ & $0.54 \mathrm{C}, \mathrm{cd}$ & $0.06 \mathrm{E}, \mathrm{f}$ & $0.17 \mathrm{E}, \mathrm{d}$ & $0.08 \mathrm{D}, \mathrm{d}$ & $0.19 \mathrm{E}, \mathrm{e}$ \\
\hline
\end{tabular}

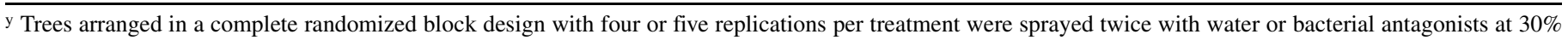
and 70\% bloom. Bacterial antagonists were Pseudomonas fluorescens A506, the extracellular protease-deficient mutant A506 aprX::Tn5, Pantoea vagans C9-1S,

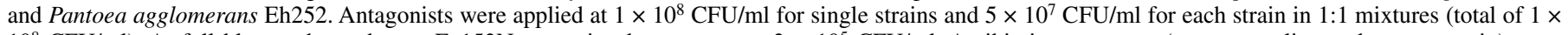
$\left.10^{8} \mathrm{CFU} / \mathrm{ml}\right)$. At full bloom, the pathogen Ea153N was misted onto trees at $3 \times 10^{5} \mathrm{CFU} / \mathrm{ml}$. Antibiotic treatments (oxytetracycline and streptomycin) were applied at $70 \%$ bloom and repeated within $36 \mathrm{~h}$ after inoculation with the streptomycin- and oxytetracycline-sensitive pathogen E. amylovora $153 \mathrm{~N}$.

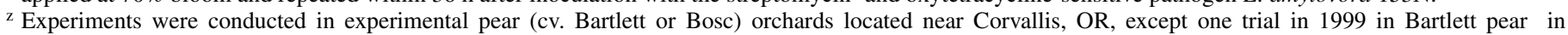
Medford, OR (Medford). Significant differences in the relative disease incidence by Fisher's protected least significant difference, $P=0.05$, are indicated by different letters within a column. Incidence data were grouped by Pantoea strain prior to analysis. Uppercase letters represent mean separation of disease incidence on trees treated with C9-1S, C9-1S in combination with A506 or its mutant, A506 and its mutant alone, water, and antibiotics. Lowercase letters represent mean separation of disease incidence on trees treated with Eh252, Eh252 in combination with A506 or its mutant, A506 and its mutant alone, water, and antibiotics. Numbers in parentheses are the average number of fire blight strikes on water-treated trees; NT = not tested. 
tically significant control of fire blight in each of the five field experiments of this study. They reduced the incidence of fire blight by an average of 68 to $71 \%$ among the five trials, a level of disease control approaching that of streptomycin, which remains the most effective antibiotic for management of fire blight caused by streptomycin-sensitive strains of E. amylovora (13). Therefore, these mechanistically compatible strain mixtures exhibited the efficacy and reliability needed for the management of fire blight in agricultural settings.

We selected A506 aprX::Tn5 because it has a single stable miniTn 5 insertion in the chromosomal gene $a p r X$ which encodes for production of the extracellular protease that degrades the Pantocin A-like antibiotics produced by Pantoea strains C9-1 or Eh252 (1). Many peptides are catabolized by A506, cleaved by its extracellular protease and internal proteases (27). In Biolog PM assays, A506 aprX::Tn5 differed from the parental strain in reduced catabolism of certain di- and tri-peptides but not carbohydrates and amino acids reported on pear stigmas (21). The nonspecific extracellular protease AprX (1) likely cleaves more peptides than those detected by differential catabolic profiles of A506 and A506 aprX::Tn5 in the Biolog PM assay, because overlapping proteolytic activities of intercellular proteases probably masked some of the substrates degraded by AprX. The extracellular protease may also break down peptides and proteins on flowers, thereby providing additional nutrients for multiplication and survival of A506. However, a contribution of the extracellular protease to growth or epiphytic fitness was not observed in this study because the growth rate of A506 aprX::Tn5 in culture and its epiphytic fitness on pear flowers was similar to the wild-type strain A506 (Table 2). It is possible that the extracellular protease of A506 degrades proteinaceous substrates on flowers to products that can be utilized as nutrient sources by other microorganisms, including the pathogen E. amylovora. Although A506 was similar to A506 aprX::Tn5 in suppressing fire blight when all field trials were considered together in our statistical analyses, it was less effective in four of five trials. Additional study is required to determine whether the extracellular protease-deficient mutant is consistently more efficacious than A506.

In this and other studies $(20,27,31,34)$, A506 significantly reduced fire blight in some trials but not when several studies were considered together. As noted previously, the lack of consistent disease control by A506 in this study may be inherent to experiments in which A506 is evaluated in small-scale, pathogeninoculated trials without antibiotics $(20,27,31,34)$. A506 provided significant control of fire blight in trials conducted in large, noninoculated commercial pear orchards also treated with antibiotics (15-17). The results of these large-scale trials indicate that A506 can be a valuable component of an integrated program incorporating antibiotics, sanitation, and biological control for management of fire blight.

The Pantoea strains Eh252 and C9-1S individually were effective biological control agents for fire blight. The efficacy of Eh252 and C9-1S was similar to that provided by oxytetracycline, which is used primarily in regions with streptomycin-resistant populations of E. amylovora $(13,18,30)$. The level of control of fire blight by Eh252 and C9-1S in this study is similar to that obtained in other orchard trials $(14,20,26,27,31,33,34,41)$. In addition to the Pantocin A-like antibiotic herbicolin O, C9-1S produces another uncharacterized antibiotic in culture called herbicolin I (5). The role of this compound in fire blight suppression by $\mathrm{C} 9-1$ in orchards has not been determined previously. Our experiments did not indicate that the capacity to produce herbicolin I in addition to herbicolin O contributes to biological control because the level of disease suppression afforded by C9-1S was not statistically different from that of Eh252, which does not produce herbicolin I. Nonetheless, disease control with the single strains of Pantoea spp. was variable among trials: 12 to $88 \%$ with Eh252 and 22 to $60 \%$ with C9-1S (Table 4). Although the disease incidence was significantly reduced by $\mathrm{C} 9-1 \mathrm{~S}$ and Eh252, control was more variable with these single-strain inoculants than with the strains combined with A506 aprX::Tn5.

A correlation between suppression of epiphytic populations of E. amylovora by bacterial antagonists and the incidence of fire blight was observed in previous studies $(10,19,20,26,27)$. In this study, the Pantoea spp. reduced the establishment of the pathogen on flowers (Table 3) but correlations between measured epiphytic populations of the pathogen on flowers treated with mixtures and eventual disease incidence were not observed. Because the number of flowers on trees considered for disease assessments far exceeds the number of flowers assayed for pathogen populations, differences in efficacy among treatments were more accurately assessed by measuring disease incidence.

Mixtures of A506 and biocontrol strains of Pantoea spp. are ecologically compatible; while co-inhabiting floral surfaces, the antagonists of the two genera can establish the epiphytic population sizes needed for suppression of the pathogen $(10,19,27,34)$. In most of the trials in this study, C9-1S and Eh252 established greater populations on flowers when combined with A506 than expected based on replacement series analyses (Figs. 1 and 2). These results are similar to those from another study where, in three of seven trials, populations of $\mathrm{C} 9-1 \mathrm{R}$ on flowers were significantly greater when combined with A506 than when applied as a single-strain inoculant (27). When C9-1S or Eh252 were combined with A506 aprX::Tn5 in the present study, populations of the Pantoea strains on flowers were greater in four of six trials compared with the populations established by single-strain inoculants. Thus, the population sizes of Pantoea spp. were generally greater in the presence of A506 regardless of extracellular protease production (Figs. 1 and 2). Populations of A506 aprX::Tn5 were unaffected by co-colonization of flowers with the Pantoea strains. This also was observed by Johnson et al. (8), who found that $\mathrm{C} 9-1 \mathrm{~S}$ and a mutant of A506 with a deletion in $a p r X$ were equal competitors on detached pear, apple, and blackberry flowers maintained in growth chambers. Overall, treatment of flowers with these intergeneric mixtures of antagonists results in greater populations of biological control strains on flowers compared with single-strain inoculants. Although the intergeneric mixtures of antagonists were ecologically compatible and established large populations on flowers, the combination of A506 with Pantoea spp. did not improve disease control compared with single-strain inoculants here or in earlier studies $(27,31,34)$. We now attribute the variation in control efficacy of these mixtures to mechanistic incompatibility caused by the extracellular protease of A506, which inactivates a peptide antibiotic produced by biocontrol strains of Pantoea spp. In some trials, the mixture of A506 with C9-1S or Eh252 provided significant control of fire blight (Table 4). In these cases, a possible explanation is that the spatial distribution of the antagonists on the stigmas was such that the secreted protease did not interact with the antibiotic produced by C9-1S or Eh252 and antibiosis still contributed to suppression of E. amylovora.

In this study, the RAUPC of the Pantoea spp. applied as single strains or in combination with A506 or the extracellular proteasedeficient mutant were positively correlated with degree-days and negatively correlated with the incidence of rain during bloom (Fig. 3). Low temperatures and frequent light rain events are often coincident in Oregon during the spring $(12,26)$; thus, these environmental factors generally are not independent. In this study, however, heavy rains ( $\geq 10 \mathrm{~mm}$ in $24 \mathrm{~h}$ ) and warm temperatures occurred during bloom in Medford in 2000 (Table 1). Based on our model of the relationship between air temperature and observed population sizes (Fig. 3), antagonist populations in Medford 2000 should have reached $\approx \log _{10} 7.1$ CFU/flower, whereas they were measured at $\log _{10} 4.8$ to $5.4 \mathrm{CFU} /$ flower (Table 2 ). The pathogen introduced at low populations was not detected on flowers in Medford 2000 in spite of mean maximum tempera- 
tures $\left(>18^{\circ} \mathrm{C}\right)$ (Table 1) that support rapid growth of E. amylovora on flowers (32). Rain is often cited as important in the fire blight disease cycle, because water facilitates migration of the pathogen from stigmas to infection sites on the nectary and also dilutes sugar concentrations on flowers to levels supportive of rapid growth (32). In this study, frequent heavy rains reduced measured bacterial populations, perhaps by repeatedly displacing bacteria from flowers. During the brief bloom period, there may not have been sufficient time to permit bacterial populations to rebound fully. In this study, excluding the Medford 2000 data from the analyses, there was a clear indication that warmer temperatures coupled with light rainfall supported bacterial multiplication of single inoculants and mixed inoculants on flowers similarly (Fig. $3)$. Although the bloom phenology and temperature-based decision aids developed for deployment of bacterial antagonists for fire blight (12) should be directly applicable for timing of applications of intergeneric mixtures, the model may need to be adjusted to account for heavy rains that may depress epiphytic populations on flowers.

Given that strains C9-1S and Eh252 were effective antagonists for fire blight control, why should mechanistically compatible intergeneric mixtures of antagonists be considered for disease control? First, the mixtures often resulted in greater populations of Pantoea spp. established on flowers compared with singlestrain inoculants. Second, disease control by the compatible mixtures was less variable among trials than the single-strain Pantoea inoculants. Inconsistent efficacy of bacterial antagonists is a major impediment that dissuades growers from using biocontrol-based disease management programs. Third, intergeneric mixtures of antagonists may reduce colonization of flowers with indigenous proteolytic bacteria. The observed variation in disease control by single-strain inoculants of Pantoea spp. such as Eh252 and C9-1S may be due to interference with antibiosis similar to that proposed with A506. Pseudomonads are common inhabitants of pear flowers in Oregon and Washington (28). Extracellular metalloprotease is common in Pseudomonas spp.; orthologs of aprX identified by reciprocal best-hit analysis are present in the genomes of many Pseudomonas spp. and in all strains of Pseudomonas fluorescens that have been sequenced to date. The colonization of flowers treated with Pantoea spp. by indigenous pseudomonads was not examined in this study but we anticipate that Pantoea spp. combined with A506 aprX::Tn5 may exclude and suppress growth of indigenous proteolytic Pseudomonas spp. on flowers better than single strains of Pantoea spp. Thus, the deployment of mixtures of Pantoea spp. with an extracellular metalloprotease-deficient mutant of A506 may lead to more consistent management of fire blight and provide a useful and predictable disease management tool, especially in areas where streptomycin has lost effectiveness due to resistance of the pathogen $(13,18,30)$.

\section{ACKNOWLEDGMENTS}

We thank L. M. Anderson, M. Brodhagen, B. Busch, N. Chaney, K. Ferguson, M. Henkels, C. Press, T. Sawyer, C. Taormina, and C. Whistler for excellent technical assistance. This study was supported, in part, by funds from the United States Department of Agriculture (USDA) NRICGP 9702924, USDA Cooperative State Research, Education and Extension Service Crops at Risk 2007-03034, and the Winter Pear Control Committee.

\section{LITERATURE CITED}

1. Anderson, L. M., Stockwell, V. O., and Loper, J. E. 2004. An extracellular protease of Pseudomonas fluorescens inactivates antibiotics of Pantoea agglomerans. Phytopathology 94:1228-1234.

2. Bochner, B.R., Giovannetti, L., and Viti, C. 2008. Important discoveries from analysing bacterial phenotypes. Mol. Microbiol. 70:274-280.

3. Davis, L. A., and Ishimaru, C. A. 1993. Cloning and expression of herbicolin $\mathrm{O}$ biosynthesis genes in Escherichia coli. (Abstr.) Phytopathology 83:1339.

4. Ishimaru, C. A., and Klos, E. J. 1984. New medium for detecting Erwinia amylovora and its use in epidemiological studies. Phytopathology 74:1342-1345.

5. Ishimaru, C. A., Klos, E. J., and Brubaker, R. R. 1988. Multiple antibiotic production by Erwinia herbicola. Phytopathology 78:746-750.

6. Jin, M., Liu, L., Wright, S. A. I., Beer, S. V., and Clardy, J. 2003. Structural and functional analysis of Pantocin A: an antibiotic from Pantoea agglomerans discovered by heterologous expression of cloned genes. Angew. Chem. Int. Ed. 42:2898-2901.

7. Jin, M., Wright, S. A. I., Beer, S. V., and Clardy, J. 2003. The biosynthetic gene cluster of Pantocin A provides insights into biosynthesis and a tool for screening. Angew. Chem. Int. Ed. 42:2902-2905.

8. Johnson, K. B., Sawyer, T. L., Stockwell, V. O., and Temple, T. N. 2009. Implications of pathogenesis by Erwinia amylovora on rosaceous stigmas to biological control of fire blight. Phytopathology 99:128-138.

9. Johnson, K. B., and Stockwell, V. O. 1998. Management of fire blight: a case study in microbial ecology. Annu. Rev. Phytopathol. 36:227-248.

10. Johnson, K. B., Stockwell, V. O., McLaughlin, R. J., Sugar, D., Loper J. E., and Roberts, R. G. 1993. Effect of bacterial antagonists on establishment of honey bee-dispersed Erwinia amylovora in pear blossoms and on fire blight control. Phytopathology 83:995-1002.

11. Johnson, K. B., Stockwell, V. O., and Sawyer, T. L. 2004. Adaptation of fire blight forecasting to optimize the use of biological controls. Plant Dis. 88:41-48.

12. Johnson, K. B., Stockwell, V. O., Sawyer, T. L., and Sugar, D. 2000. Assessment of environmental factors influencing growth and spread of Pantoea agglomerans on and among blossoms of pear and apple. Phytopathology 90:1285-1294.

13. Jones, A. L., and Schnabel, E. L. 2000. The development of streptomycinresistant strains of Erwinia amylovora. Pages 235-252 in: Fire Blight: The Disease and Its Causative Agent, Erwinia amylovora. J. L. Vanneste, ed. CAB International, London.

14. Kearns, L. P., and Mahanty, H. K. 1998. Antibiotic production by Erwinia herbicola Eh1087: Its role in inhibition of Erwinia amylovora and partial characterization of antibiotic biosynthesis genes. Appl. Environ. Microbiol. 64:1837-1844.

15. Lindow, S. E. 1985. Integrated control and role of antibiosis in biological control of fire blight and frost injury. Pages 83-115 in: Biological Control on the Phylloplane. C. E. Windels and S. E. Lindow, eds. American Phytopathological Society, St. Paul, MN.

16. Lindow, S. E., McGourty, G., and Elkins, R. 1996. Interactions of antibiotics with Pseudomonas fluorescens A506 in the control of fire blight and frost injury of pear. Phytopathology 86:841-848.

17. Lindow, S. E., and Suslow, T. V. 2003. Temporal dynamics of the biocontrol agent Pseudomonas fluorescens strain A506 in flowers in inoculated pear trees. Phytopathology 93:727-737.

18. Loper, J. E., Henkels, M. D., Roberts, R. G., Grove, G. G., Willet, M. J., and Smith, T. J. 1991. Evaluation of streptomycin and oxytetracycline and copper resistance of Erwinia amylovora isolated from pear orchards in Washington state. Plant Dis. 75:287-290.

19. Nuclo, R. L., Johnson, K. B., Stockwell, V. O., and Sugar, D. 1997. Secondary colonization of pear blossoms by two bacterial antagonists of the fire blight pathogen. Plant Dis. 82:661-668.

20. Pusey, P. L. 2002. Biological control agents for fire blight of apple compared under conditions limiting natural dispersal. Plant Dis. 86:639644.

21. Pusey, P. L. Rudell, D. R., Curry, E. A., and Mattheis, J. P. 2008. Characterization of stigma exudates in aqueous extracts from apple and pear flowers. HortScience 43:1471-1478.

22. Pusey, P. L., Stockwell, V. O., and Rudell, D. R. 2008. Antibiosis and acidification by Pantoea agglomerans strain E325 may contribute to suppression of Erwinia amylovora. Phytopathology 98:1136-1143.

23. Rezzonico, F., Vogel, G., Duffy, B., and Tonolla, M. 2010. Application of whole-cell matrix-assisted laser desorption ionization-time of flight mass spectrometry application for rapid identification and clustering analysis of Pantoea species. Appl. Environ. Microbiol. 76:4497-4509.

24. Stockwell, V. O., Johnson, K. B., and Loper, J. E. 1996. Compatibility of bacterial antagonists of Erwinia amylovora with antibiotics used to control fire blight. Phytopathology 86:834-840.

25. Stockwell, V. O., Johnson, K. B., and Loper, J. E. 1998. Establishment of bacterial antagonists of Erwinia amylovora on pear and apple blossoms as influence by inoculum preparation. Phytopathology 88:506-513.

26. Stockwell, V. O., Johnson, K. B., Sugar, D., and Loper, J. E. 2002. Antibiosis contributes to biological control of fire blight by Pantoea agglomerans strain Eh252 in orchards. Phytopathology 92:1202-1209.

27. Stockwell, V. O., Johnson, K. B., Sugar, D., and Loper, J. E. 2010. Control of fire blight by Pseudomonas fluorescens A506 and Pantoea vagans C9-1 applied as single strains and mixed inocula. Phytopathology 
100:1330-1339.

28. Stockwell, V. O., McLaughlin, R. J., Henkels, M. D., Loper, J. E., Sugar, D., and Roberts, R. G. 1999. Epiphytic colonization of pear stigmas and hypanthia by bacteria during primary bloom. Phytopathology 89:11621168.

29. Stockwell, V. O., and Stack, J. P. 2007. Using Pseudomonas spp. for integrated biological control. Phytopathology 97:244-249.

30. Stockwell, V. O., Sugar, D., Spotts, R., Johnson, K. B., and Loper, J. E. 1996. Recovery of streptomycin-resistant isolates of Erwinia amylovora from Oregon orchards. (Abstr.) Phytopathology 86:S50.

31. Sundin, G. W., Werner, N. A., Yoder, K. S., and Aldwinckle, H. S. 2009. Field evaluation of biological control of fire blight in the eastern United States. Plant Dis. 93:386-394.

32. Thomson, S. V. 2000. Epidemiology of fire blight. Pages 9-36 in: Fire Blight: The Disease and Its Causative Agent, Erwinia amylovora. J. L. Vanneste, ed. CAB International, London.

33. Vanneste, J. L. 1996. Honey bees and epiphytic bacteria to control fire blight, a bacterial disease of apple and pear. Biocontrol News Inf. $17: 67 \mathrm{~N}-78 \mathrm{~N}$.

34. Vanneste, J. L., and Yu, J. 1996. Biological control of fire blight using Erwinia herbicola Eh252 and Pseudomonas fluorescens A506 separately or in combination. Acta Hortic. 411:351-354.
35. Vanneste, J. L., Yu, J., and Beer, S. V. 1992. Role of antibiotic production by Erwinia herbicola Eh252 in biological control of Erwinia amylovora. J. Bacteriol. 174:2785-2796.

36. Vanneste, J. L., Yu, J., and Cornish, D. A. 2008. Presence of genes homologous to those necessary for synthesis of microcin mccEh252 in strains of Pantoea agglomerans. Acta Hortic. 793:391-393.

37. Wilson, M., and Lindow, S. E. 1993. Interactions between the biological control agent Pseudomonas fluorescens strain A506 and Erwinia amylovora in pear blossoms. Phytopathology 83:117-123.

38. Wilson, M., and Lindow, S. E. 1994. Ecological similarity and coexistence of epiphytic ice-nucleating (Ice+) Pseudomonas syringae strains and a non-ice-nucleating (Ice-) biological control agent. Appl. Environ. Microbiol. 60:3128-3137.

39. Wodzinski, R. S., and Paulin, J.-P. 1994. Frequency and diversity of antibiotic production by putative Erwinia herbicola strains. J. Appl. Bacteriol. 76:603-607.

40. Wodzinski, R. S., Umholtz, T. E., Rundle, J. R., and Beer, S. V. 1994. Mechanisms of inhibition of Erwinia amylovora by Erw. herbicola in vitro and in vivo. J. Appl. Bacteriol. 76:22-29.

41. Wright, S. A. I., Zumoff, C. H., Schneider, L., and Beer, S. V. 2001. Pantoea agglomerans strain Eh318 produces two antibiotics that inhibit Erwinia amylovora in vitro. Appl. Environ. Microbiol. 67:284-292.

\section{Erratum}

The following sentence should be included in the third full paragraph on page 121 and the reference below should be cited for this new sentence.

"In addition to the Pantocin A-like antibiotic herbicolin $\mathrm{O}, \mathrm{C} 9-1 \mathrm{~S}$ produces another antibiotic in culture called herbicolin I (5), which was recently identified as 2-amino-3-(oxirane-2,3-dicarboxamido)-propanoyl-valine."

"Sammer, U. F., Völksch, B., Möllmann, U., Schmidtke, M., Spiteller, P., Spiteller, M., and Spiteller, D. 2009. 2-Amino-3-(oxirane-2,3dicarboxamido)-propanoyl-valine, an effective peptide antibiotic from the epiphyte Pantoea agglomerans 48b/90. Appl. Environ. Microbiol. 75:7710-7717." 